\title{
Gestational age at initiation of 17-alpha hydroxyprogesterone caproate and recurrent preterm birth
}

\author{
Angela Ning, BA; Catherine J. Vladutiu, PhD; Sarah K. Dotters-Katz, MD; William H. Goodnight, MD; \\ Tracy A. Manuck, MD, MSCI
}

BACKGROUND: Preterm birth is the leading cause of neonatal morbidity and mortality in nonanomalous neonates in the United States. Women with a previous early spontaneous preterm birth are at highest risk for recurrence. Weekly intramuscular 17-alpha hydroxyprogesterone caproate reduces the risk of recurrent prematurity. Although current guidelines recommend 17-alpha hydroxyprogesterone caproate initiation between 16 and 20 weeks, in clinical practice, 17-alpha hydroxyprogesterone caproate is started across a spectrum of gestational ages. OBJECTIVE: The objective of the study was to examine the relationship between the gestational age at 17-alpha hydroxyprogesterone caproate initiation and recurrent preterm birth among women with a prior spontaneous preterm birth 16-28 weeks' gestation.

STUDY DESIGN: This was a retrospective cohort study of women from a single tertiary care center, 2005-2016. All women with $\geq 1$ singleton preterm births because of a spontaneous onset of contractions, preterm prelabor rupture of membranes, or painless cervical dilation between 16 and 28 weeks followed by a subsequent singleton pregnancy treated with 17-alpha hydroxyprogesterone caproate were included. Women were grouped based on quartiles of gestational age of 17-alpha hydroxyprogesterone caproate initiation (quartile $1,14^{0 / 7}$ to $16^{1 / 7}$; quartile 2 , $16^{2 / 7}$ to $17^{0 / 7}$; quartile $3,17^{1 / 7}$ to $18^{6 / 7}$; and quartile $4,19^{0 / 7}$ to $27^{5 / 7}$ ). Women with a gestational age of 17-alpha hydroxyprogesterone caproate initiation in quartiles 1 and 2 were considered to have early-start 17-alpha hydroxyprogesterone caproate; those in quartiles 3 and 4 were considered to have late-start 17 -alpha hydroxyprogesterone caproate. The primary outcome was recurrent preterm birth $<37$ weeks' gestation. Secondary outcomes included recurrent preterm birth $<34$ and $<28$ weeks' gestation and composite major neonatal morbidity (diagnosis of grade III or IV intraventricular hemorrhage, periventricular leukomalacia, bronchopulmonary dysplasia, necrotizing enterocolitis stage II or III, or death). Gestational age at delivery was compared by quartile of 17-alpha hydroxyprogesterone caproate initiation using Kaplan-Meier survival curves and the log-rank test. Logistic regression models estimated odds ratios for the association between gestational age at 17-alpha hydroxyprogesterone caproate initiation and preterm birth $<37$ weeks' gestation, adjusting for demographics, prior pregnancy and antenatal characteristics.

RESULTS: A total of 132 women met inclusion criteria; 52 (39.6\%) experienced recurrent preterm birth $<37$ weeks in the studied pregnancy. 17-Alpha hydroxyprogesterone caproate was initiated at a mean $17^{6 / 7} \pm$ 2.5 weeks. Demographic and baseline characteristics were similar between women with early-start 17-alpha hydroxyprogesterone caproate (quartiles 1 and 2) compared with those with late-start 17-alpha hydroxyprogesterone caproate (quartiles 3 and 4). Women with earlystart 17-alpha hydroxyprogesterone caproate trended toward lower rates of recurrent preterm birth $<37$ weeks compared with those with late-start 17-alpha hydroxyprogesterone caproate (41.3\% vs $57.7 \%, P=$ .065). Delivery gestational age was inversely proportional to gestational age at 17-alpha hydroxyprogesterone caproate initiation (quartile 1,37/7 weeks vs quartile $2,36^{5 / 7}$ vs quartile $3,36^{1 / 7}$ weeks vs quartile $4,34^{0 / 7}$, $P=.007)$. In Kaplan-Meier survival analyses, these differences in delivery gestational age by 17-alpha hydroxyprogesterone caproate initiation quartile persisted across pregnancy (log-rank $P<.001$ ). In regression models, later initiation of 17-alpha hydroxyprogesterone caproate was significantly associated with increased odds of preterm birth $<37$ weeks. Women with early 17 -alpha hydroxyprogesterone caproate initiation also had lower rates of major neonatal morbidity than those with later 17 -alpha hydroxyprogesterone caproate initiation (1.5\% vs $14.3 \%$, $P=.005)$.

CONCLUSION: Rates of recurrent preterm birth among women with a prior spontaneous preterm birth 16-28 weeks are high. Women beginning 17-alpha hydroxyprogesterone caproate early deliver later and have improved neonatal outcomes. Clinicians should make every effort to facilitate 17-alpha hydroxyprogesterone caproate initiation at 16 weeks.

Key words: preterm birth, progesterone, recurrent preterm birth, spontaneous preterm birth
$\mathrm{P}$ reterm birth (PTB) continues to be the leading cause of neonatal morbidity and mortality. Prematurity is the leading cause of death in children under age 5 years and contributes to short- and long-term disability in countless survivors. ${ }^{1,2}$

In the United States, after a brief period of decline, the rates of PTB increased between 2014 and 2015 and remain unacceptably high, at $9.6 \%{ }^{1}$ Unfortunately, recent trends toward a decline in overall PTB rates have not been consistent across all gestational ages, and the rate of early PTB $(<34$ weeks' gestation) has remained static, at $3.41 \%$ in 2012 (up from $3.32 \%$ in
1990). ${ }^{2}$ Although early PTB affects smaller numbers of neonates, those born $<34$ weeks are more likely to die in the first year of life. Survivors of early PTB are at greatest risk for increased utilization of resources in early life, need for early intervention services, and reduced school performance compared with babies born late preterm or at term. ${ }^{3-8}$

A history of a prior spontaneous PTB is the greatest risk factor predicting risk for recurrence. This risk is even greater among women with multiple prior PTB 
and those with a prior early PTB, including caused by a cervical insufficiency phenotype. ${ }^{9-12}$ Furthermore, РTB tends to recur at similar gestational ages $^{13-15}$; thus, women with a prior early PTB are at highest risk for significant recurrent neonatal morbidity and mortality in subsequent pregnancies.

Intramuscular 17-alpha hydroxyprogesterone caproate (17-OHPC) injections administered weekly beginning at 16-20 weeks until 36 weeks of gestation reduce the risk of recurrent PTB (relative risk, 0.66; 95\% confidence interval, $0.54-0.81)^{16}$ and may be most efficacious among women with a prior early PTB. ${ }^{17,18}$ Current clinical guidelines recommend initiation of 17-OHPC therapy between 16 and 20 weeks' gestation among women with a singleton gestation and a prior spontaneous PTB; these recommendations largely mirror the protocol followed by Meis et $\mathrm{al}^{16}$ in the large randomized controlled trial of 17-OHPC vs placebo published in 2003. ${ }^{19,20}$

In broader obstetric populations of women with a prior spontaneous PTB $<37$ weeks' gestation, results of studies examining the impact of gestational age of 17-OHPC on pregnancy outcomes have been mixed, and some reports have suggested beneficial effects with 17OHPC initiated as late as 28 weeks' gestation. $^{21}$

The purpose of this study was to examine the relationship between the gestational age at 17-OHPC initiation and recurrent spontaneous PTB among women at high risk for recurrent PTB: those with a history of spontaneous PTB 16-28 weeks' gestation.

\section{Materials and Methods}

This is a retrospective cohort of women delivering at University of North Carolina (UNC) Hospitals from 2005 through 2016. We included women with $\geq 1$ previous documented singleton nonanomalous delivery between 16 and 28 weeks' gestation because of spontaneous indications who received at least 1 dose of 17-OHPC prophylaxis in a subsequent singleton pregnancy with delivery of that subsequent pregnancy at UNC.
We defined spontaneous PTB as delivery following preterm prelabor rupture of membranes, idiopathic preterm labor (painful uterine contractions leading to cervical dilation and eventual delivery), or cervical insufficiency (painless dilation of the cervix in midpregnancy, or asymptomatic cervical shortening $<25 \mathrm{~mm}$ prior to 24 weeks' gestation with subsequent delivery at $<28$ weeks) as documented in the medical record.

Women whose index delivery at $<28$ weeks was due to medical or fetal indications (eg, because of preeclampsia or fetal indications such as growth restriction) or was spontaneous but complicated by major fetal anomalies or aneuploidy were excluded. Gestational age was determined from standard algorithms using the last menstrual period and ultrasound criteria. ${ }^{22}$

Women were initially identified by searching diagnostic and discharge codes from the UNC Perinatal Database, an established, comprehensive registry of women including all women delivering at UNC. Only the most recent subsequent pregnancy was considered for women who had multiple pregnancies following the index spontaneous PTB at $<28$ weeks.

Prenatal care was provided at the discretion of the clinician, with consultation or primary management by maternal-fetal medicine providers as needed. The UNC Division of MaternalFetal Medicine publishes online algorithms as a service to providers in North Carolina to assist the primary obstetric provider in the clinical management of a variety of pregnancy complications and standardized care throughout the state (www.mombaby.org).

Electronic medical records were manually verified and abstracted to ensure eligibility and to obtain additional clinical data for this study. This study was approved by the Institutional Review Board at the University of North Carolina at Chapel Hill.

Gestational age of 17-OHPC initiation was abstracted and categorized into quartiles (quartile $1,14^{0 / 7}$ to $16^{1 / 7}$; quartile $2,16^{2 / 7}$ to $17^{0 / 7}$; quartile $3,17^{1 / 7}$ to $18^{6 / 7}$; quartile $4,19^{0 / 7}$ to $27^{5 / 7}$ ).
Women with a gestational age of 17OHPC initiation in quartiles 1 and 2 were considered to have early-start 17OHPC, and those in quartiles 3 and 4 were considered to have late-start 17OHPC. Demographic, obstetric history, and antenatal characteristics were compared between women with earlyand late-start 17-OHPC. This included assessing the timing of prenatal care initiation and gestational age at the first obstetric ultrasound.

The primary outcome was $\mathrm{PTB}$ at $<37$ weeks' gestation. Secondary outcomes included PTB at $<34$ and $<28$ weeks' gestation and composite neonatal morbidity (defined as 1 or more of the following prior to initial hospital discharge: grade III or IV intraventricular hemorrhage, periventricular leukomalacia, bronchopulmonary dysplasia, necrotizing enterocolitis requiring surgery, or death).

Kaplan-Meier survival curves were used to compare the gestational age at delivery by quartile of 17-OHPC initiation and were compared with the logrank test. Bivariate analyses comparing cohort characteristics and neonatal outcomes by early and late start were conducted using $\chi^{2}$, Fisher exact, and analysis of variance, as appropriate. Logistic regression models estimated odds ratios for the association between quartiles of 17-OHPC initiation and PTB $<37$ weeks.

Stepwise regression with backward elimination was performed to select an adjusted model. We initially included all variables significant in bivariate analyses; those factors with $P<.20$ were retained in final regression models. Further variables were excluded until no further significant change in the final model was noted based on $\mathrm{R}^{2}$. All analyses were performed using STATA version 13.1 (College Station, TX).

\section{Results}

A total of 132 women met inclusion criteria. 17-OHPC was initiated at a mean $17^{6 / 7} \pm 2.5$ weeks (median $17^{0 / 7}$ weeks, interquartile range $16^{2 / 7}$ to $18^{6 / 7}$ weeks). Ninety-five women $(72.0 \%)$ initiated 17-OHPC within the recommended 16-20 week gestational age 
window, whereas $15(11.3 \%)$ started at less than 16 weeks and 22 (16.7\%) began 17 -OHPC at $\geq 20$ weeks.

Demographic and baseline characteristics were similar between 69 women with early-start 17-OHPC and 63 with late-start 17-OHPC; specifically, there were no differences in race, prepregnancy body mass index, delivery gestational age of the penultimate pregnancy, number of pregnancies after the index $<28$ week PTB, or rate of cerclage placement in the current gestation (Table 1). However, women with earlystart 17-OHPC were more likely to be married (Table 1).
The vast majority of women $(92.2 \%)$ received prenatal care and/or had an obstetrical ultrasound prior to 16 weeks; only $2(1.7 \%)$ initiated care at $\geq 20$ weeks. Less than half were cared for primarily by a maternal-fetal medicine physician, a proportion that did not differ by 17-OHPC initiation group, but women with late start were less likely to receive their prenatal care primarily at UNC Hospitals and clinics, although this did not reach statistical significance (Table 1). Nearly half of women $(47 \%)$ had a history of cervical insufficiency prior to the studied pregnancy, and 54/ $132(41 \%)$ had a cerclage placed during pregnancy; rates of cervical insufficiency and cerclage placement were similar in the early- and late-start 17-OHPC groups (Table 1). Of note, Table 1 findings were similar when all 4 quartiles were compared instead of collapsing groups into early- and late-start 17OHPC groups.

Fifty-two women (39\%) delivered at $<37$ weeks. Recurrent PTB at $<37$ weeks was less common among women with early-start 17-OHPC compared with those with late-start $17-\mathrm{OHPC}, 41.3 \%$ vs $57.7 \%(P=.065)$, although this did not reach statistical significance (Table 2). However, women with early-start 17-

TABLE 1

Demographic, obstetric history, and antenatal characteristics

\begin{tabular}{|c|c|c|c|}
\hline Characteristics & $\begin{array}{l}\text { Early } 17-0 \mathrm{HPC} \text { initiation } \\
(\mathrm{Q} 1 \text { and } \mathrm{Q} 2), 14^{0 / 7} \text { to } 17^{1 / 7} \\
(\mathrm{n}=69)\end{array}$ & $\begin{array}{l}\text { Late } 17-0 \mathrm{OHPC} \text { initiation } \\
(\mathrm{Q} 3 \text { and } \mathrm{Q} 4), 17^{2 / 7} \text { to } 27^{5 / 7} \\
(\mathrm{n}=63)\end{array}$ & $P$ value \\
\hline Black race & $33(47.8)$ & $32(50.8)$ & .733 \\
\hline Married & $39(56.5)$ & $20(31.8)$ & .004 \\
\hline Prepregnancy $\mathrm{BMI} \geq 30 \mathrm{~kg} / \mathrm{m}^{2}$ & $32(46.4)$ & $30(47.6)$ & .719 \\
\hline Gestational age of earliest prior PTB (mean weeks, \pm SD) & $22.3 \pm 3.1$ & $22.1 \pm 3.3$ & .675 \\
\hline $\begin{array}{l}\text { Delivery gestational age of penultimate pregnancy } \\
\text { reaching } \geq 14 \text { weeks (mean weeks, } \pm \text { SD) }\end{array}$ & $27.5 \pm 7.7$ & $28.4 \pm 7.0$ & .463 \\
\hline History of $\geq 1$ prior term deliveries & $30(43.5)$ & $32(50.8)$ & .400 \\
\hline $\begin{array}{l}\text { Number of previous PTB }<37 \text { weeks' gestation } \\
\text { (median, IQR) }\end{array}$ & $1(1,2)$ & $1(1,2)$ & .157 \\
\hline History of cervical insufficiency in $\geq 1$ prior pregnancy & $33(53.2)$ & $20(40.0)$ & .163 \\
\hline $\begin{array}{l}\text { Number of pregnancies after index }<28 \text { wks PTB } \\
\text { (median, IQR) }\end{array}$ & $2(1,3)$ & $2(1,2)$ & .912 \\
\hline $\begin{array}{l}\text { First prenatal visit or initial obstetric ultrasound }<12 \\
\text { weeks' gestation }\end{array}$ & $48 / 60(80.0)$ & $36 / 55(65.5)$ & .079 \\
\hline $\begin{array}{l}\text { First prenatal visit or initial obstetric ultrasound }<16 \\
\text { weeks' gestation }\end{array}$ & $58 / 60(96.7)$ & $48 / 55(87.3)$ & .084 \\
\hline $\begin{array}{l}\text { Primary site of prenatal care was University of North } \\
\text { Carolina hospitals and clinics }\end{array}$ & 65 (94.2) & $51(82.3)$ & 052 \\
\hline $\begin{array}{l}\text { Received some or all prenatal care with maternal-fetal } \\
\text { medicine physician this pregnancy }\end{array}$ & $33(47.8)$ & $25(39.7)$ & .346 \\
\hline Cervical length $<25 \mathrm{~mm}$ during current pregnancy ${ }^{\mathrm{a}}$ & $10(19.6)$ & $7(14.9)$ & .538 \\
\hline Cerclage placed this pregnancy & $32(46.4)$ & $22(34.9)$ & .181 \\
\hline Received vaginal progesterone $>14$ wks this pregnancy & $6(8.7)$ & $5(7.9)$ & $>.99$ \\
\hline Received antenatal corticosteroids & $17(24.6)$ & $17(27.0)$ & .758 \\
\hline
\end{tabular}


Pregnancy and neonatal outcomes by gestational age at 17-OHPC initiation

\begin{tabular}{|c|c|c|c|}
\hline Variables & $\begin{array}{l}\text { Early 17-OHPC initiation } \\
(\mathrm{Q} 1 \text { and } \mathrm{Q} 2), 14^{0 / 7} \text { to } 17^{1 / 7} \\
(\mathrm{n}=69)\end{array}$ & $\begin{array}{l}\text { Later } 17-0 H P C \text { initiation } \\
\left(\mathrm{Q3} \text { and Q4), } 17 \mathrm{w}^{2} \mathrm{~d} \text { to } 28 \mathrm{w}^{0} \mathrm{~d}\right. \\
(\mathrm{n}=63)\end{array}$ & $P$ value \\
\hline Delivery gestational age (weeks \pm SD) & $37.0 \pm 3.1$ & $35.0 \pm 5.1$ & .008 \\
\hline Developed gestational diabetes & $5(7.3)$ & $5(7.9)$ & $>.990$ \\
\hline Preeclampsia or gestational hypertension & $3(4.4)$ & $3(4.8)$ & $>.990$ \\
\hline Vaginal delivery & $32(46.4)$ & $29(46.0)$ & .968 \\
\hline Birthweight (grams \pm SD) & $2908 \pm 775$ & $2507 \pm 1035$ & .012 \\
\hline Delivered $<37$ wks & $22(31.9)$ & $30(47.6)$ & .065 \\
\hline Delivered $<34$ wks & $10(14.5)$ & $18(28.6)$ & .048 \\
\hline Delivered $<28$ wks & $1(1.5)$ & $8(12.7)$ & .014 \\
\hline Male infant & $37(54.4)$ & $29(46.0)$ & .338 \\
\hline Intraventricular hemorrhage, grade I or II & $1(1.5)$ & $1(1.6)$ & $>.990$ \\
\hline Major neonatal morbidity & $1(1.5)$ & $9(14.3)$ & .007 \\
\hline Neonatal death & $1(1.5)$ & $4(6.4)$ & .192 \\
\hline Bronchopulmonary dysplasia & $0(0)$ & $4(6.4)$ & .049 \\
\hline Intraventricular hemorrhage, grade III or IV & $0(0)$ & $1(1.6)$ & .480 \\
\hline Periventricular leukomalacia & $0(0)$ & $1(1.6)$ & .477 \\
\hline Necrotizing enterocolitis, stage II or III & $0(0)$ & $2(3.2)$ & .226 \\
\hline
\end{tabular}

17-OHPC, 17-alpha hydroxyprogesterone caproate; $P T B$, preterm birth; $Q$, quartile.

Ning et al. Gestational age of 17-OHPC initiation and risk of recurrent PTB. Am J Obstet Gynecol 2017.

OHPC had a later mean delivery gestational age $(37.0 \pm 3.1$ weeks vs $35.0 \pm 5.1$ weeks for women with late-start 17OHPC $[P=.008])$.

These differences in rates of recurrent $\mathrm{PTB}<37$ weeks and delivery gestational age by 17-OHPC start were even more pronounced when examining quartiles, in which both rates of recurrent PTB at $<37$ weeks (quartile 1, $21.2 \%$ vs quartile $2,41.7 \%$ vs quartile $3,43.3 \%$ vs quartile $4,51.5 \%$ preterm $<37$ weeks [ $P=.076]$ ) and delivery gestational age were consistently inversely proportional to gestational age at 17-OHPC initiation (quartile $1,37^{4 / 7}$ weeks vs quartile 2, $36^{5 / 7}$ vs quartile $3,36^{1 / 7}$ weeks vs quartile $\left.4,34^{0 / 7}[P=.007]\right)$.

Differences in mean delivery gestational age were statistically significant across gestation in the Kaplan-Meier survival curve $(\log$ rank $P<.001$; Figure). Similar findings were appreciated for recurrent PTB at $<34$ and $<28$ weeks' gestation (Table 2). Rates of major composite neonatal morbidity were higher among women with late-start 17OHPC initiation (Table 2).

In logistic regression models, later initiation of 17-OHPC was associated with increased odds of PTB when adjusting for confounders (Table 3). Each later quartile of initiation was associated with an elevated risk compared with the first quartile, which served as the referent group. Women with a short cervical length $(<25 \mathrm{~mm})$ in the midtrimester also were at increased risk for recurrent PTB in the model; women with a prepregnancy body mass index $\geq 30 \mathrm{~kg} / \mathrm{m}^{2}$ and those with the earliest prior gestational ages of their earliest prior deliveries had a decreased risk for recurrent PTB in the final model (Table 3).

\section{Comment}

We found that women with a prior singleton spontaneous PTB at $<28$ weeks are at high risk for recurrent PTB at $<37$ weeks' gestation despite 17OHPC therapy. Individuals who initiated 17-OHPC therapy at earlier gestational ages had the lowest recurrence of PTB across a spectrum of gestational ages. These differences were observed despite the overwhelming majority (>90\%) initiating prenatal care or having an initial obstetric ultrasound prior to 16 weeks' gestation. Thus, these very high-risk women entered care early and most had the opportunity to begin 17-OHPC prophylaxis within the recommended time of 16-20 weeks' gestation. Despite this, $16 \%$ initiated 17 OHPC after 20 weeks.

Other studies have investigated the relationship between gestational age at 17-OHPC initiation and delivery gestational age in obstetric cohorts that included women with a prior spontaneous PTB up to 36 weeks' gestation. How et $\mathrm{al}^{23}$ evaluated 599 women initiating 17-OHPC between 16 and 21 weeks and 307 women initiating 17OHPC between 21 and 27 weeks and found no significant difference in spontaneous PTB at $<37$ weeks between the 2 


\section{FIGURE}

\section{Probability of remaining pregnant by gestational age at 17-OHPC initiation}

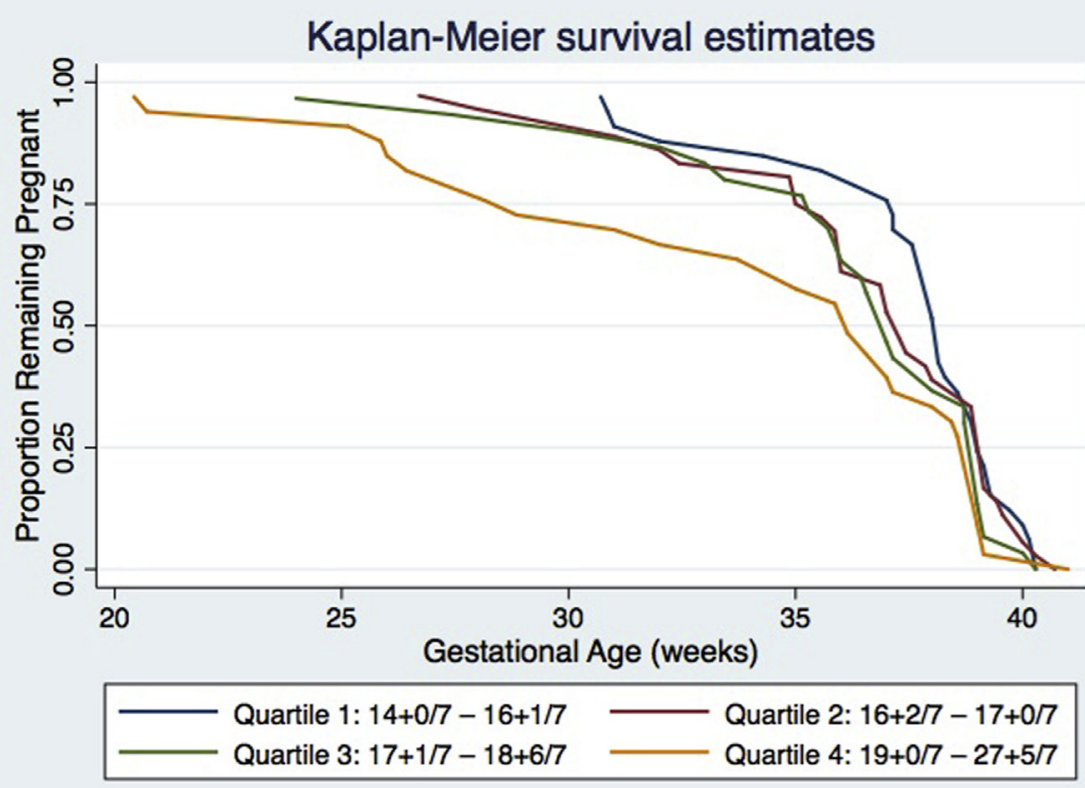

17-OHPC, 17-alpha hydroxyprogesterone caproate.

Ning et al. Gestational age of 17-OHPC initiation and risk of recurrent PTB. Am J Obstet Gynecol 2017. groups $(33 \%$ vs $36 \%),<35$ weeks $(16 \%$ vs $17 \%)$, or $<32$ weeks ( $6 \%$ vs $4 \%$ ).

In contrast, Gonzalez-Quintero et $\mathrm{al}^{24}$ studied 156 women initiating 17-OHPC at $16-20$ weeks and compared them with 119 women initiating 17-OHPC between 21 and 26 weeks and noted lower rates of spontaneous PTB among those initiating therapy earlier (in the $16-20$ week time period; $26 \%$ vs $37 \%$

\section{TABLE 3}

\section{Adjusted odds ratios for the association between 17-0HPC initiation and preterm birth $<37$ weeks among women with $\geq 1$ prior spontaneous $16-28$ week deliveries}

\begin{tabular}{|c|c|c|}
\hline Variables & $\begin{array}{l}\text { Adjusted odds ratio } \\
\text { for PTB }(95 \% \mathrm{Cl})^{\mathrm{a}}\end{array}$ & $P$ value \\
\hline \multicolumn{3}{|l|}{ Gestational age at start of $17-\mathrm{OHPC}$} \\
\hline$Q 1,14^{0 / 7}$ to $16^{2 / 7}$ & 1.0 (referent) & - \\
\hline Q2, $16^{2 / 7}$ to $17^{0 / 7}$ & $4.2(1.3,13.7)$ & .020 \\
\hline Q3, $17^{1 / 7}$ to $18^{6 / 7}$ & $4.3(1.3,14.6)$ & .019 \\
\hline Q4, $19^{0 / 7}$ to $27^{5 / 7}$ & $5.3(1.6,17.5)$ & .006 \\
\hline Cervical length $<25 \mathrm{~mm}$ & $4.2(1.2,15.0)$ & .027 \\
\hline Prepregnancy body mass index $\geq 30 \mathrm{~kg} / \mathrm{m}^{2}$ & $0.4(0.2,0.9)$ & .028 \\
\hline $\begin{array}{l}\text { Gestational age of earliest prior delivery } \\
\text { (per week of completed pregnancy) }\end{array}$ & $0.9(0.8,1.0)$ & .045 \\
\hline
\end{tabular}

Cl, confidence interval; 17-OHPC, 17-alpha hydroxyprogesterone caproate; PTB, preterm birth; $Q$, quartile.

${ }^{a}$ Additional factors considered in the model were black race, cerclage in current pregnancy, gestational age of penultimate delivery, and marital status; these factors were excluded from the final model (all $P \geq .20$ ).

Ning et al. Gestational age of 17-OHPC initiation and risk of recurrent PTB. Am J Obstet Gynecol 2017.
$[P=.065])$ within the overall cohort. Furthermore, a significant reduction in PTB with earlier initiation was noted among the subset of women who had more than 1 prior PTB $(27 \%$ vs $39 \%$ $[P=.039]) .^{24}$

However, neither of these studies examined the gestational age of the earliest prior PTB as a risk factor influencing outcomes in relation to the initiation of 17-OHPC, which may be a possible explanation for the difference in our results and those of How et al. ${ }^{23}$

Limited studies of prematurity specialty clinics have demonstrated improved outcomes with reductions in the rate of PTB among women provided with specific education, frequent visits, and treatment with consistent evidencebased algorithms. ${ }^{25-27}$ Iams and colleagues ${ }^{28}$ recently examined data from a prematurity clinic in Ohio, which provided accelerated access to prenatal care for women with a prior spontaneous PTB. In that clinic, earlier access to care facilitated earlier initiation of 17-OHPC, and rates of recurrent prematurity dropped. However, it was difficult to disentangle the effects of early, focused prenatal care (likely received by the women who started 17-OHPC early) from the effects of early initiation of 17OHPC. The majority of women in this cohort (73.0\%) initiated prenatal care in the first trimester, and $92.2 \%$ initiated prenatal care or had an initial obstetric ultrasound by 16 weeks' gestation. This suggests that the correlation we have noted between earlier 17-OHPC initiation and later delivery gestational age and improved neonatal outcomes is not due merely to earlier prenatal care.

Our study has several limitations. Quartiles of gestational age at 17-OHPC initiation were defined by the distribution of 17-OHPC initiation in this population. However, similar methodology has been utilized in other studies of prematurity to evaluate the relationship between an exposure and an outcome when the ideal cutoff for the exposure is uncertain but a dose-response effect is suspected. ${ }^{29}$ Furthermore, the majority of women in the first quartile of gestational age at 17-OHPC initiation began therapy prior to the American College of 
Obstetricians and Gynecologists's recommended start time of 16 weeks' gestation. Although there is no evidence to suggest that initiation prior to 16 weeks is associated with harm, efficacy with initiation $<16$ weeks has not been evaluated in high-quality randomized controlled trials and therefore cannot be recommended based on the results of the current analysis.

The number of subjects in each quartile of 17-OHPC administration may limit the precision of the estimated effect as demonstrated by the wide confidence interval. Further investigation with a greater sample size may clarify the trends in influence in 17-OHPC initiation over gestational ages or may suggest an optimal gestational age cutpoint for maximal 17-OHPC effect.

Finally, we did not have consistent information regarding the number of prenatal visits attended to evaluate the effects of prenatal care and 17-OHPC compliance on pregnancy outcomes, given the variable locations of prenatal care in this cohort. The lack of availability of specific prenatal care in this data set also limits investigation into reasons to explain the variability in timing of initiation of 17P.

Our study has several strengths. This is a relatively large cohort of women with a very high a priori risk for recurrent PTB. We had detailed information on demographics and prior pregnancies and were able to confirm that the prior PTB were due to spontaneous indications. We have provided evidence of improved outcomes when 17-OHPC is started earlier in pregnancy. Beginning 17-OHPC at 16 weeks' gestation is a simple recommendation with potential for a clinically significant impact on pregnancy outcomes, the timing of which can be easily facilitated at the time of the initial prenatal visit.

In conclusion, women with a prior PTB at 16-28 weeks' gestation are at high risk for recurrent PTB in subsequent pregnancies. Outcomes are improved when 17-OHPC is initiated between 14 and $17^{1 / 7}$ weeks' gestation, a time frame including the lower end of the gestational age window recommended by the American College of
Obstetricians and Gynecologists and the Society of Maternal-Fetal Medicine. Clinicians should make every effort to facilitate 17-OHPC initiation at 16 weeks. Future studies should confirm these findings, elucidate the potential mechanisms behind these effects, and evaluate whether earlier initiation (eg, 14-16 weeks) may be more appropriate for certain subsets of women, including those at highest risk for recurrent PTB.

\section{References}

1. Martin JA, Hamilton BE, Osterman MJ. Births in the United States, 2015. NCHS Data Brief 2016:1-8.

2. Martin JA, Hamilton BE, Osterman MJ, Driscoll AK, Mathews TJ. Births: final data for 2015. Natl Vital Stat Rep 2017;66:1.

3. Russell RB, Green NS, Steiner CA, et al. Cost of hospitalization for preterm and low birth weight infants in the United States. Pediatrics 2007;120:e1-9.

4. Manuck TA, Rice MM, Bailit JL, et al. Preterm neonatal morbidity and mortality by gestational age: a contemporary cohort. Am J Obstet Gynecol 2016;215:103.e1-14.

5. Manuck TA, Sheng X, Yoder BA, Varner MW. Correlation between initial neonatal and early childhood outcomes following preterm birth. Am J Obstet Gynecol 2014;210:426.e1-9.

6. Natarajan G, Shankaran S. Short- and longterm outcomes of moderate and late preterm infants. Am J Perinatol 2016;33:305-17.

7. Bodeau-Livinec F, Marlow N, Ancel PY, Kurinczuk JJ, Costeloe K, Kaminski M. Impact of intensive care practices on short-term and longterm outcomes for extremely preterm infants: comparison between the British Isles and France. Pediatrics 2008;122:e1014-21.

8. Vohr B. Long-term outcomes of moderately preterm, late preterm, and early term infants. Clin Perinatol 2013;40:739-51.

9. Adams MM, Elam-Evans LD, Wilson HG, Gilbertz DA. Rates of and factors associated with recurrence of preterm delivery. JAMA 2000;283:1591-6.

10. Simonsen SE, Lyon JL, Stanford JB, Porucznik CA, Esplin MS, Varner MW. Risk factors for recurrent preterm birth in multiparous Utah women: a historical cohort study. BJOG 2013;120:863-72.

11. Sneider K, Christiansen OB, Sundtoft IB, Langhoff-Roos J. Recurrence of second trimester miscarriage and extreme preterm delivery at 16-27 weeks of gestation with a focus on cervical insufficiency and prophylactic cerclage. Acta Obstet Gynecol Scand 2016;95: 1383-90.

12. McManemy J, Cooke E, Amon E, Leet $T$. Recurrence risk for preterm delivery. Am J Obstet Gynecol 2007;196:576.e1-6. discussion e6-7.
13. Bloom SL, Yost NP, McIntire DD, Leveno KJ. Recurrence of preterm birth in singleton and twin pregnancies. Obstet Gynecol 2001;98:379-85. 14. Esplin MS, O'Brien E, Fraser A, et al. Estimating recurrence of spontaneous preterm delivery. Obstet Gynecol 2008;112:516-23.

15. Monson MA, Gibbons KJ, Esplin MS, Varner MW, Manuck TA. Pregnancy outcomes in women with a history of previable, preterm prelabor rupture of membranes. Obstet Gynecol 2016;128:976-82.

16. Meis PJ, Klebanoff M, Thom E, et al. Prevention of recurrent preterm delivery by 17 alpha-hydroxyprogesterone caproate. N Engl J Med 2003;348:2379-85.

17. Spong CY. Prediction and prevention of recurrent spontaneous preterm birth. Obstet Gynecol 2007:110:405-15.

18. Manuck TA, Stoddard GJ, Fry RC, Esplin MS, Varner MW. Nonresponse to 17 alpha hydroxyprogesterone caproate for recurrent spontaneous preterm birth prevention: clinical prediction and generation of a risk scoring system. Am J Obstet Gynecol 2016;215:622.e1-8.

19. Committee on Practice Bulletins-Obstetrics - The American College of Obstetricians and Gynecologists. Prediction and prevention of preterm birth. ACOG Practice bulletin no. 130. Obstet Gynecol 2012;120:964-73.

20. Society for Maternal-Fetal Medicine Publications Committee. The choice of progestogen for the prevention of preterm birth in women with singleton pregnancy and prior preterm birth. Am J Obstet Gynecol 2017;216:B11-3.

21. Mason MV, Poole-Yaeger A, Krueger CR, House KM, Lucas B. Impact of 17P usage on $\mathrm{NICU}$ admissions in a managed medicaid population-a five-year review. Manag Care 2010; 19:46-52.

22. Carey JC, Klebanoff MA, Hauth JC, et al. Metronidazole to prevent preterm delivery in pregnant women with asymptomatic bacterial vaginosis. National Institute of Child Health and Human Development Network of Maternal-Fetal Medicine Units. N Engl J Med 2000;342:534-40.

23. How HY, Barton JR, Istwan NB, Rhea DJ, Stanziano GJ. Prophylaxis with 17 alphahydroxyprogesterone caproate for prevention of recurrent preterm delivery: does gestational age at initiation of treatment matter? Am J Obstet Gynecol 2007;197:260.e1-4.

24. Gonzalez-Quintero VH, Istwan NB, Rhea DJ, Smarkusky L, Hoffman MC, Stanziano GJ. Gestational age at initiation of 17hydroxyprogesterone caproate (17P) and recurrent preterm delivery. I Matern Fetal Neonatal Med 2007;20:249-52.

25. Multicenter randomized, controlled trial of a preterm birth prevention program. Collaborative Group on Preterm Birth Prevention. Am J Obstet Gynecol 1993;169:352-66.

26. Hobel CJ, Ross MG, Bemis RL, et al. The West Los Angeles Preterm Birth Prevention Project. I. Program impact on high-risk women. Am J Obstet Gynecol 1994;170:54-62. 
27. Manuck TA, Henry E, Gibson J, et al. Pregnancy outcomes in a recurrent preterm birth prevention clinic. Am J Obstet Gynecol 2011;204:320.e1-6.

28. Markham KB, Walker H, Lynch CD, lams JD. Preterm birth rates in a prematurity prevention clinic after adoption of progestin prophylaxis. Obstet Gynecol 2014;123:34-9.

29. Caritis SN, Venkataramanan R, Thom E, et al. Relationship between 17-alpha hydroxyprogesterone caproate concentration and spontaneous preterm birth. Am J Obstet Gynecol 2014;210:128.e1-6.

\section{Author and article information}

From the University of North Carolina School of Medicine (Ms Ning) and Division of Maternal-Fetal Medicine, Department of Obstetrics and Gynecology (Drs Vladutiu, Dotters-Katz, Goodnight, and Manuck), University of North Carolina School of Medicine, Chapel Hill, NC.
Received March 4, 2017; revised May 4, 2017; accepted May 5, 2017.

The authors report no conflict of interest.

Presented in part as a poster presentation (final abstract number 329) at the 37th annual meeting of the Society for Maternal-Fetal Medicine, Las Vegas, NV, Jan. 26, 2017.

Corresponding author: Tracy A. Manuck, MD. tmanuck@med.unc.edu 